\title{
Vascularized fibular epiphyseal transplantation for limb salvage following bone tumour excision
}

\author{
Lisa M Becker MD ${ }^{1}$, Ronald M Zuker MD FRCSC FACS FAAP ${ }^{2}$ \\ ${ }^{I}$ Department of Surgery, The University of Toronto and ${ }^{2}$ Division of Plastic Surgery, The Hospital for \\ Sick Children, Toronto, Ontario
}

\begin{abstract}
LM Becker, RM Zuker. Vascularized fibular epiphyseal transplantation for limb salvage following bone tumour excision. Can J Plast Surg 1999;7(2):65-73.
\end{abstract}

Vascularized fibular transplantation has found wide application for long bone reconstruction in both congenital and acquired defects. However, in children the growth of these transplants is limited and requires the epiphysis if it is to be substantial. Also, the reconstruction of a joint is best achieved with autologus hyaline cartilage. Vascularized fibular epiphyseal transplantation, thus, may play a role in limb salvage procedures in children to both preserve joint function and facilitate long bone growth. The present paper discusses the history of vascularized epiphyseal transplantation both in the laboratory and clinical realm. In discussing its advantages and associated problems, special emphasis is directed at the vascular factors, the endocrine environment, the innervation, mechanical stressors, the recipient site and the donor site. Two case examples are presented to demonstrate the technique, the results and the long term outcome.

Key Words: Epiphyseal; Fibular; Limb; Salvage; Transplantation

Transplantation des épiphyses du péroné vascularisés pour sauver un membre après excision de tumeur osseuse

RÉSUMÉ : La transplantation des épiphyses du péroné vascularisés est largement utilisée pour la reconstruction des os longs, en présence d'anomalies congénitales ou acquises. Par contre, chez les enfants, la croissance de ces transplantations est limitée et requiert l'épiphyse pour réussir. Également la reconstruction d'une articulation réussit mieux avec un cartilage hyalin autologue. La transplantation des épiphyses du péroné vascularisés peut donc jouer un rôle dans les interventions visant à sauver un membre chez les enfants tant dans la préservation de l'articulation que dans la croissance des os longs. Le présent article aborde l'historique de la transplantation des épiphyses du péroné vascularisés en laboratoire et en clinique. On en mentionne les avantages et les inconvénients en insistant sur les facteurs vasculaires, le milieu encocrinien, l'innervation, les facteurs de stress mécaniques, le site receveur et le site donneur. On présente en outre deux exemples tirés de la pratique, pour démontrer la technique, ses résultats et l'issue à long terme de l'intervention.

$\mathrm{S}_{\mathrm{r}}^{\mathrm{k}}$ keletal pathology requiring reconstruction in the paediatric population is either congenital or acquired. Acquired defects may be the result of trauma (1), tumour (2), infection (2) or ischemia, while congenital entities considered for skeletal reconstruction may be developmental, such as radial club hand (2) and pseudoarthrosis of the tibia. The goals of limb reconstruction are to stabilize the limb in all planes and to create a limb of normal length that is painless, has a func-

Correspondence and reprints: Dr RM Zuker, Division of Plastic Surgery, The Hospital for Sick Children, 555 University Avenue, Toronto, Ontario M5G 1X8. Telephone 416-813-6447, fax 416-813-6147,

e-mail ronald.zuker@sickkids.on.ca tional range of active motion and can tolerate normal stresses without degenerating. In children, maintaining normal growth potential of the limb is desired $(1,3)$.

Following the development of consistently successful microvascular anastomosis in the 1960s, vascularized grafting was applied to bone (4). It has been shown experimentally as well as in several clinical scenarios that vascularized epiphyseal transplants fulfill the criteria of limb reconstruction (2,5-10). Limb reconstruction in children is still in its early stages and each patient presents unique challenges. The present paper describes two cases where vascularized fibular transplantation was used for limb salvage following bone tumour excision. Preservation of epiphyseal growth was attempted with the aim of providing a functionally normal joint and limb. In case 1, bone decancellation was attempted to 


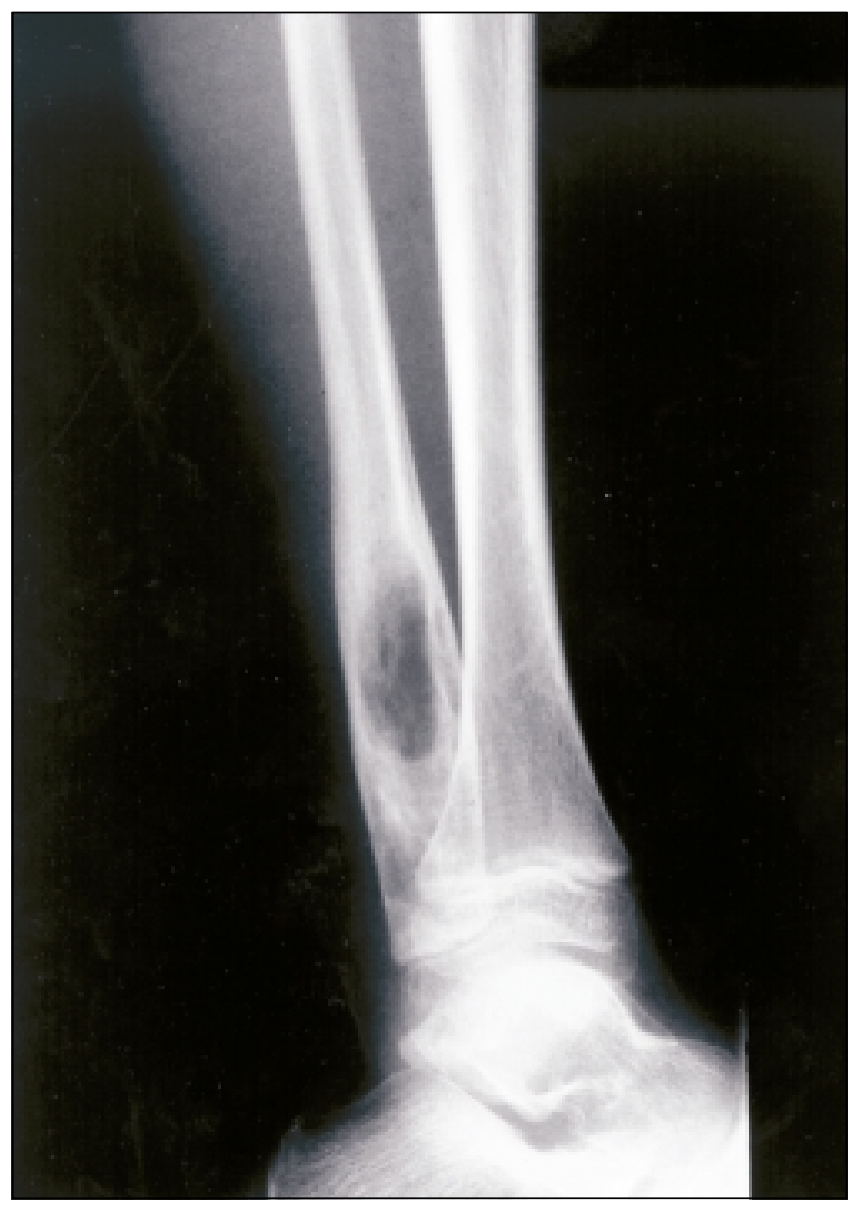

Figure 1) Case 1: Preoperative imaging of osteogenic sarcoma of the left fibula

optimize joint congruity while maintaining intact periosteum, articular cartilage and physis. In case 2, a reversed vein graft was used to provide adequate pedicle length, and multiple tendon transfers were performed to balance the hand and provide normal range of motion. These cases illustrate strategies used to overcome challenges in vascularized epiphyseal transplants. The long term results and the role of vascularized epiphyseal transplantation are discussed. Background experimental work and clinical experience are reviewed.

\section{Case 1}

\section{CASE PRESENTATIONS}

In 1986, an eight-year-old girl presented with an osteogenic sarcoma of the distal left fibula with possible tumour encroachment of the distal tibial-fibular joint (Figure 1). Following chemotherapy, the patient was prepared for free fibular metaphyseal and epiphyseal transplantation with the goal of avoiding ankle fusion and valgus deformity. The fibular tumour and ipsilateral proximal fibula with its epiphysis were accessed through a vertical incision extending from $5 \mathrm{~cm}$ proximal to the lateral knee joint to the distal lateral malleolus (Figure 2). The peroneal nerve, the popliteal artery and the lateral inferior geniculate artery (LIG) were identi-

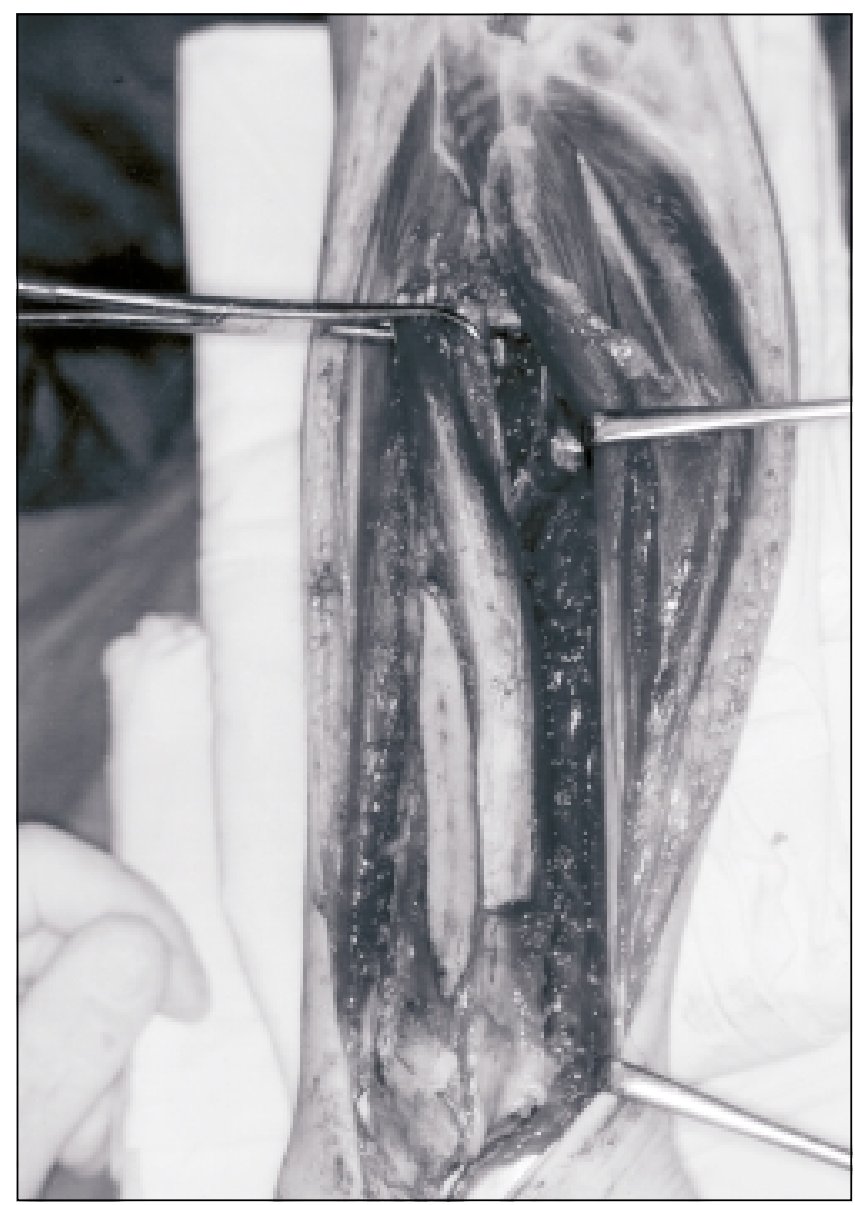

Figure 2) Case 1: Intraoperative view of the fibular transplant

fied and protected. A $16 \mathrm{~cm}$ long section of the distal fibula, including the metaphysis and distal epiphysis, and part of the distal tibial metaphysis were resected. Pathology confirmed that the margins were tumour free.

The proximal fibular epiphysis and the remaining metaphysis were prepared for transplantation as two distinct vascularized bone segments based on the LIG vessels and peroneal vessels, respectively. The bone and its two contiguous segments were harvested and rotated $180^{\circ}$, and placed in the distal ankle mortise. Rongeurs and osteotomes were used to remove the bone from the fibular head through an incision in the articular surface and periosteum. This contouring was done to optimize the congruity at the new joint of the talus, tibia and the fibular transplant. The transplanted fibula was then fixed in position as the lateral ankle stabilizer. The metaphyseal segment abutted the distal tibia and the epiphyseal end provided lateral ankle support. The peroneal vessels were anastamosed end to side to the anterior tibial vessels and the LIG vessels were anastamosed end to side to the reticular branch of the anterior tibial vessels (Figure 3). The patient received a supportive dressing, and the fibula and tibia were fused six months later. Bony union of the proximal fibular transplant and the tibia occurred, and the ankle mortise appeared stable. 


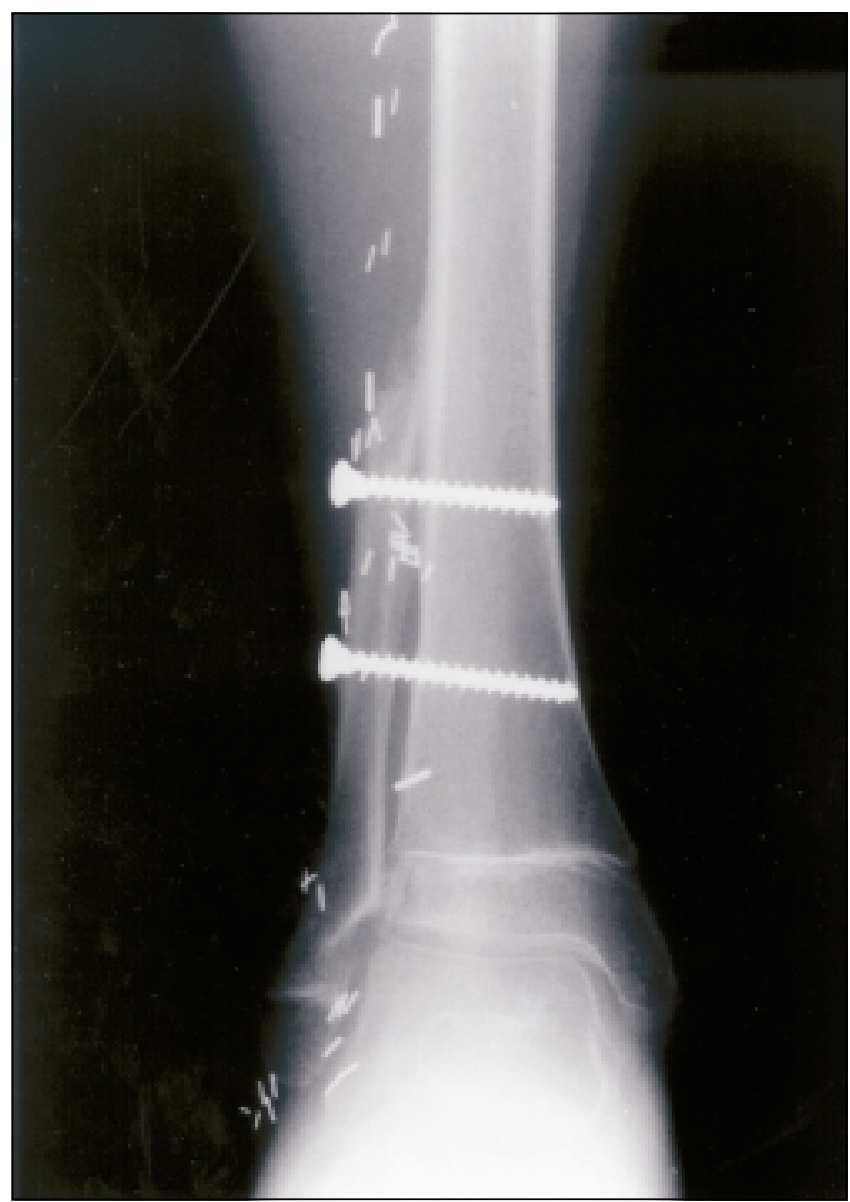

Figure 3) Case 1: Postoperative imaging of the transplanted fibula demonstrating the fixation of the fibula to the tibia and the contouring of the distal aspect of the fibula for joint congruity

At 11 months postoperatively, the lateral aspect of the tibial epiphysis had arrested, while the vascularized fibular transplant continued to grow. The result was an apparent overgrowth of the fibula with valgus deformity and ankle joint deterioration. Despite this, the patient had good function except for some inversion while walking. At 18 months postoperatively, an osteotomy of the distal tibia and fibula was performed to correct the valgus deformity. At five years following tumour resection, an epiphysiodesis of the contralateral proximal tibial epiphysis was performed to prevent worsening of a $2.7 \mathrm{~cm}$ discrepancy in leg length.

The patient is now 19 years of age and is able to ambulate normally, take part in all sporting activities and lead a normal life. She has some swelling after prolonged standing and mild discomfort after exercise, but neither of these limits her functional capabilities. She has no pain or instability at the knee or ankle. The reconstructed ankle has normal contour (Figure 4), and full passive and active range of motion (Figures 5a,b). Radiographically, the ankle mortise appears stable (Figure 6), and the fibular donor site at the knee is adequately aligned.

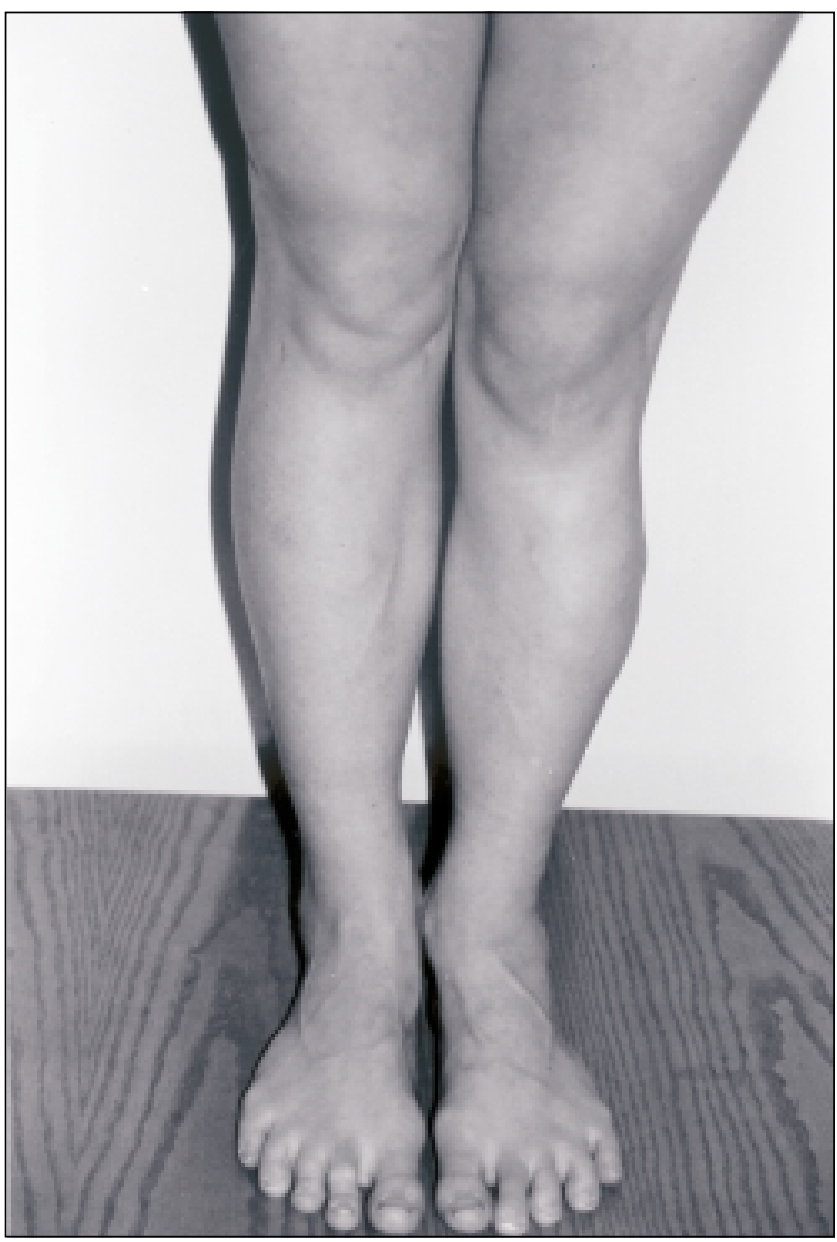

Figure 4) Case 1: A photograph taken 11 years postoperatively shows normal alignment of the affected knee and the ankle

\section{Case 2}

In 1982, a six-year-old boy presented with a Ewings sarcoma of the left calcaneus that was treated successfully with radiation and chemotherapy. Seven years later, he presented with an osteogenic sarcoma of the right distal radius (Figure 7). Following chemotherapy, the patient was prepared for tumour excision and reconstruction with a free vascularized fibular transplant. At that time, $x$-ray demonstrated an open fibular epiphysis. Under tourniquet, $16 \mathrm{~cm}$ of the distal radius containing the tumour and the affected musculature (extensor carpi radialis longus, extensor carpi radialis brevis, brachial radialis, abductor pollicis longus and flexor pollicis brevis) were resected, preserving the radial nerve, artery and vein. Pathology confirmed that the resection margins were tumour free (Figure 8).

The fibula, with a muscular cuff, and the peroneal artery and its vena commitans were harvested under tourniquet through a lateral incision extending from the knee to the lateral malleolus. An $18 \mathrm{~cm}$ long section of the proximal fibula with its epiphysis was transferred to the distal forearm and secured to the remaining proximal radius using a plate and 

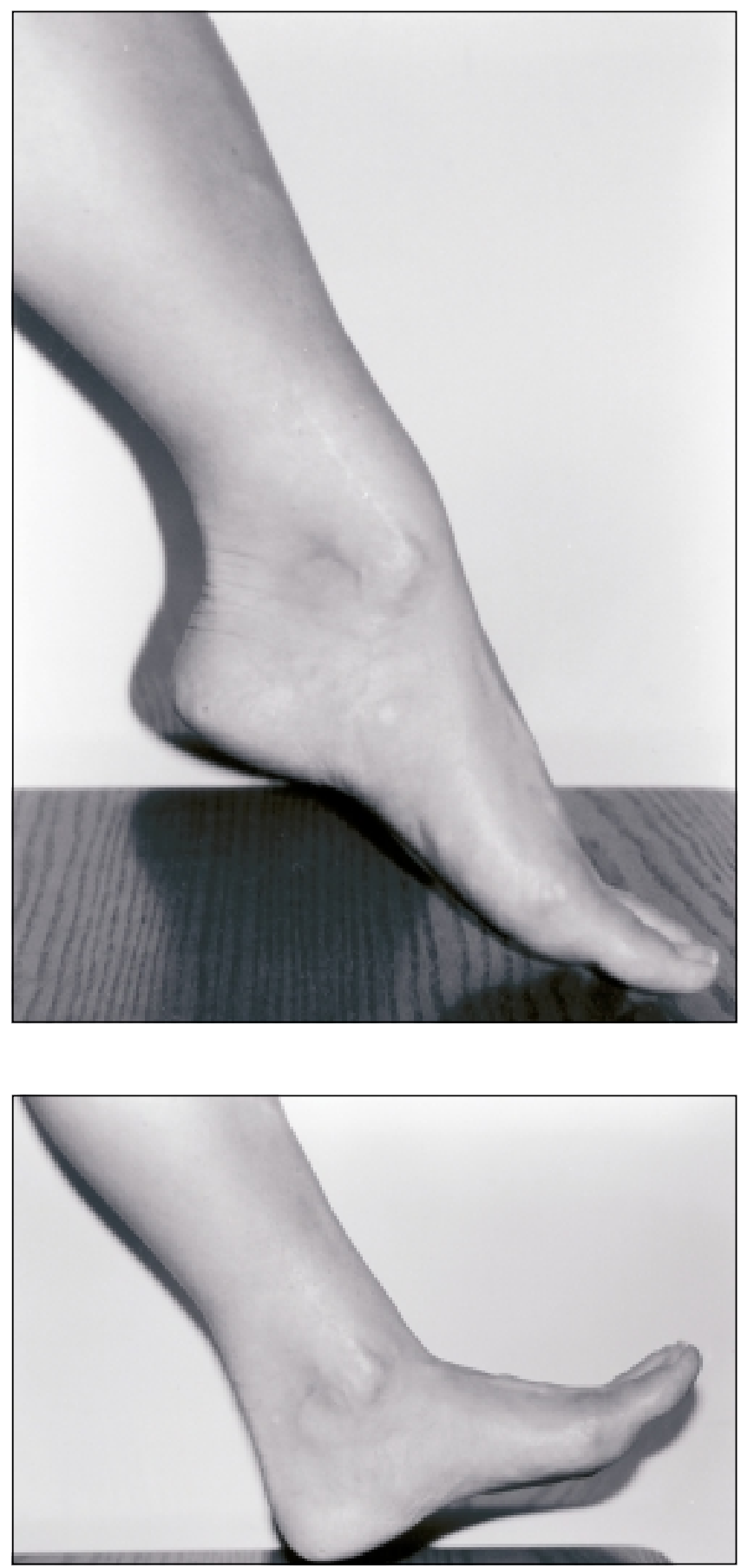

Figure 5) Case 1: At 11 years postoperatively the patient retains full range of (top) active ankle plantar flexion and (bottom) active dorsiflexion

screws (Figure 9). The peroneal artery was anastamosed end to side to the radial artery, and the accompanying vein was anastamosed to the cephalic vein with the aid of a reversed vein graft. Once patency was confirmed, muscular rebalancing of the hand was carried out using multiple tendon transfers. Extensor indices were used to provide thumb extension; flexor carpi radialis was used for wrist extension. Pronator

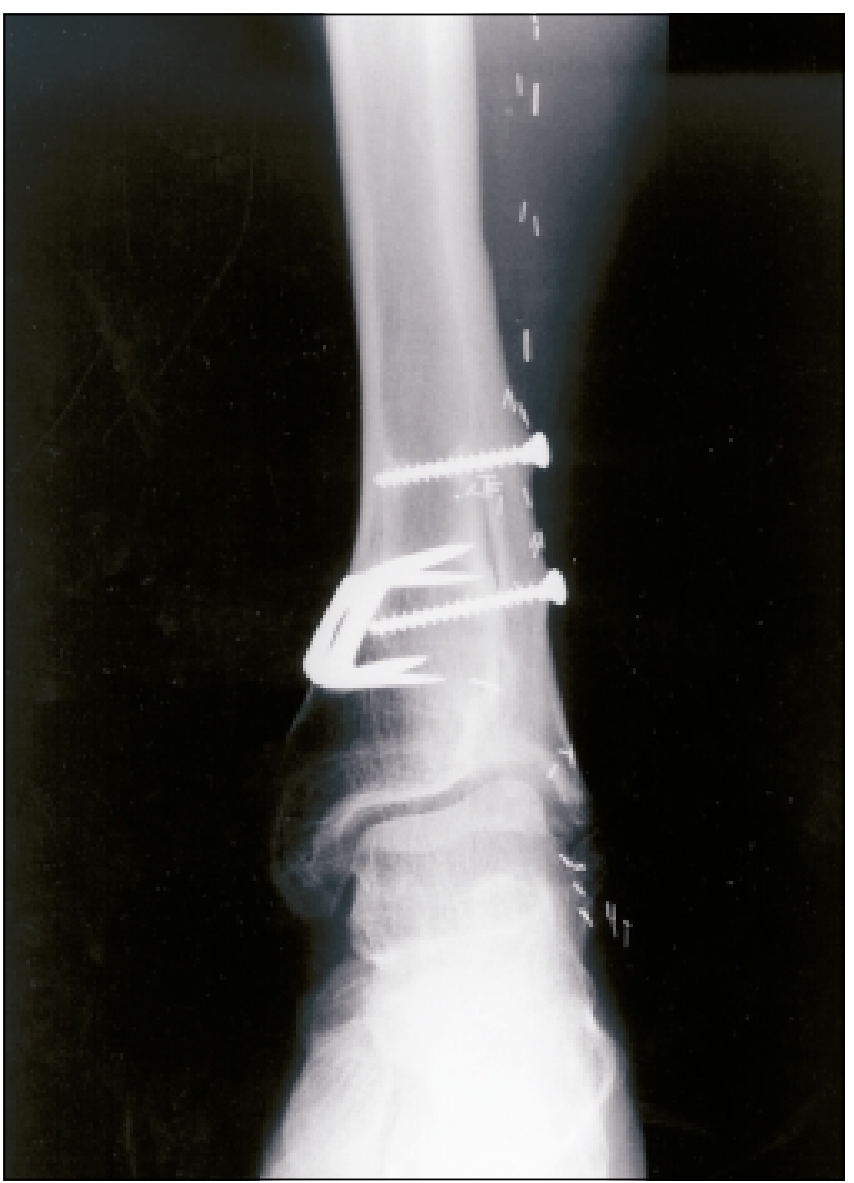

Figure 6) Case 1: An x-ray taken 11 years postoperatively demonstrates preservation of the joint space and ankle mortise with no evidence of joint deterioration

teres and the supinator muscles were sutured to the fibular graft in an attempt to provide normal axial arm movement. The arm was placed in a supportive cast for three weeks, then an active rehabilitation program was commenced (Figure 10). The patient received postoperative chemotherapy after initial healing of the wound was complete.

At one year postoperatively, the patient suffered a volar subluxation of the wrist due to ulnar-carpal ligament deficiency. The dislocation was not treated, and the patient developed sclerosis at the wrist. Three years postoperatively, his hand was functional, although limited in pronation and supination. This prevented the patient from eating and writing with his right hand. His active supination and pronation was $15^{\circ}$. His wrist, however, was able to flex $10^{\circ}$, and he had active extension to $30^{\circ}$. He had no wrist pain or instability. The fibular graft hypertrophied, confirming its vascularity and the fact that the extremity was being used. The patient did not report instability or other complications at the donor knee or ankle. He completed training in civil engineering and did not require any further therapy. After 15 years, the wrist is pain free, stable and not limiting his vocational activities (Figure 11). 


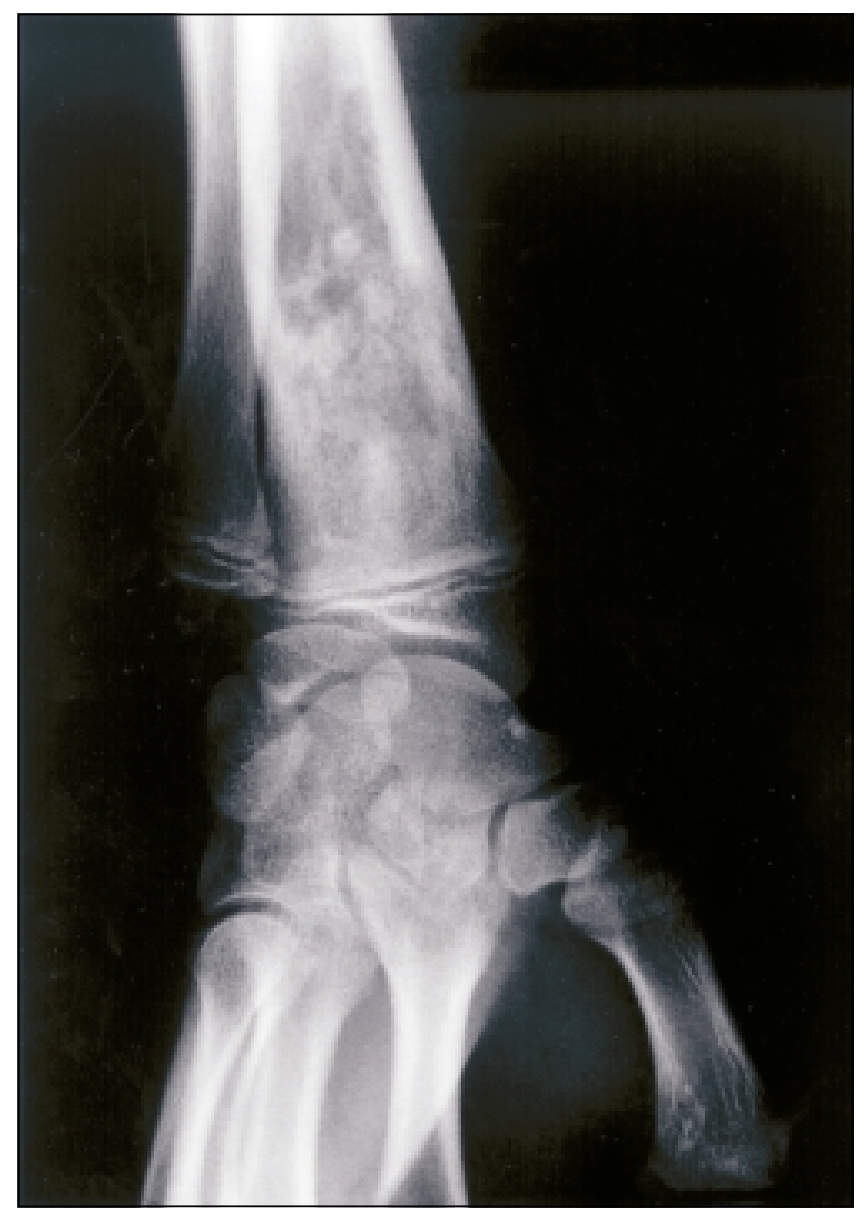

Figure 7) Case 2: Preoperative imaging of osteogenic sarcoma of the right distal radius

\section{DISCUSSION}

Vascularized epiphyseal transplantation for paediatric limb reconstruction provides a number of potential advantages over nonvascularized grafts and nonepiphyseal grafts. These advantages include improved wound healing, stability and growth. The success of these grafts is dependent on the physiology and anatomy of both the donor site and the transplant recipient site. In this discussion, the experimental and clinical data are reviewed, and an attempt is made to explain and understand the outcomes described in the present cases. Current indications and preferred techniques are outlined based on the authors' experience.

\section{Experimental work}

Since Donski et al (11) began experimental work on the vascularized transplant of epiphyseal plates in puppies in 1979, numerous animal models have been developed. Research using dogs $(9,10,12-17)$, rabbits $(18-21)$, mice $(22,23)$, rats (22) and lambs (24) has been used to demonstrate principles of epiphyseal plate transplantation using the femur (24), ulna $(15,16,24)$, whole knee joint $(19,21-23,25)$, fibula $(10,13,14,17)$, iliac crest (9) and second metatarsal (20), thus demonstrating the flexibility of this reconstructive modality. In these experimental models, vascularized grafts have lower

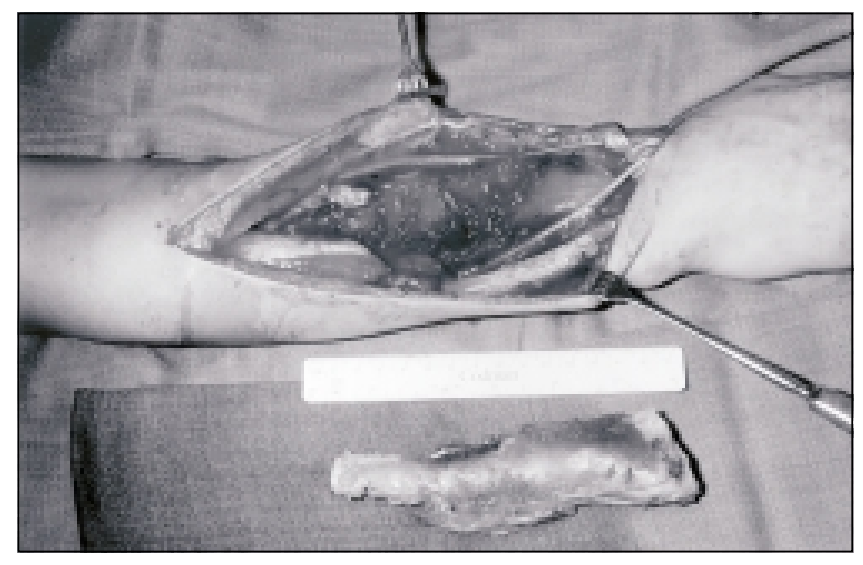

Figure 8) Case 2: Intraoperative view of the resected tumour of the radius

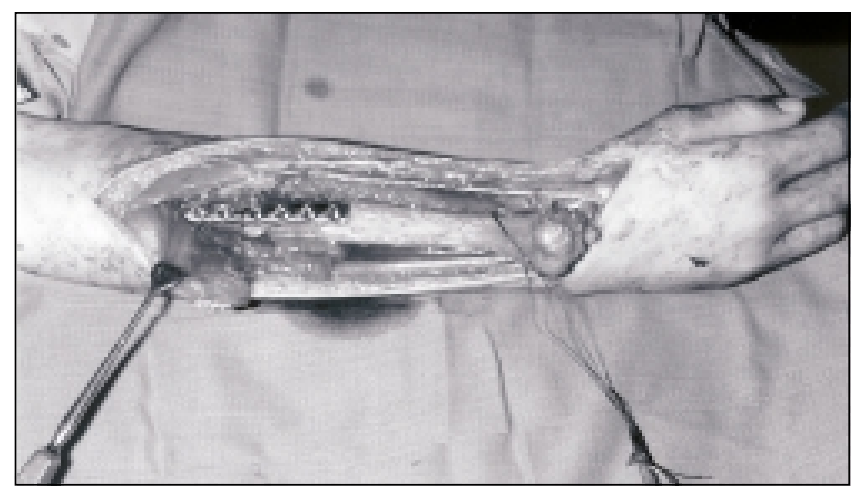

Figure 9) Case 2: Intraoperative view of the fibular transplant fixed to the remaining radius

rates of infection, decreased frequency of nonunion and shorter time to bone union compared with nonvascularized grafts (26). In addition, revascularized grafts have improved epiphyseal growth potential (11).

Physiological factors such as vascular supply, endocrine environment, innervation and previous trauma at the recipient site are known to affect survival and growth of the epiphysis (2). Anatomical factors affecting the growth potential of epiphyseal transplants include the native growth potential of the graft, and mechanical stresses at the donor and recipient sites $(12,17)$. Experimental data regarding these factors are briefly reviewed in the context of the cases described in the present paper.

Vascular factors: The physis normally receives blood from the metaphysis, the periosteum and the epiphysis $(27,28)$. When only the metaphyseal supply is intact, $63 \%$ (11) to $76 \%$ (15) of normal growth is reported, while periosteal supply alone yields $69 \%$ (8) of normal growth, and isolated epiphyseal supply produces only $42 \%$ (15) of normal growth. Near normal growth has been obtained experimentally in different models using selected pedicles supplying parts of both the epiphysis and metaphysis $(13-15,18)$. The fibular epiphysis is perfused by the LIG artery and the anterior tibial artery. The 


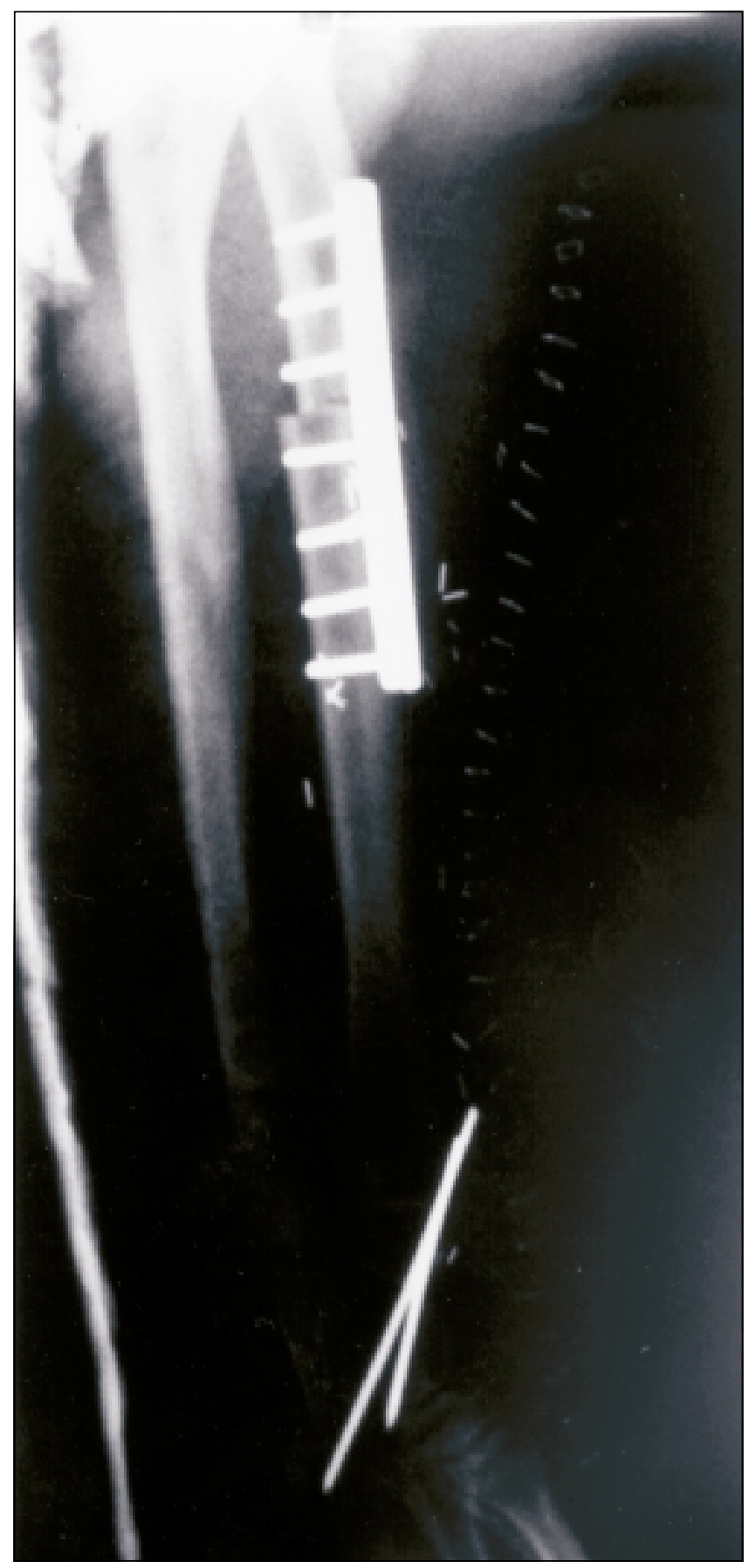

Figure 10) Case 2: Postoperative imaging of the fibular graft, remaining radius and wrist

metaphysis is supplied by the anterior tibial artery and the peroneal artery (5). The anterior tibial artery alone (5) or the peroneal artery in conjunction with the LIG artery $(7,29)$ should, therefore, be adequate to perfuse the fibular head.

It is important to determine the blood supply to the donor epiphysis preoperatively. In 1988, Taylor et al (5) used angiography to study the perfusion of the fibular epiphysis in cadavers; vascular anomalies occurred in $21 \%$ of cases.

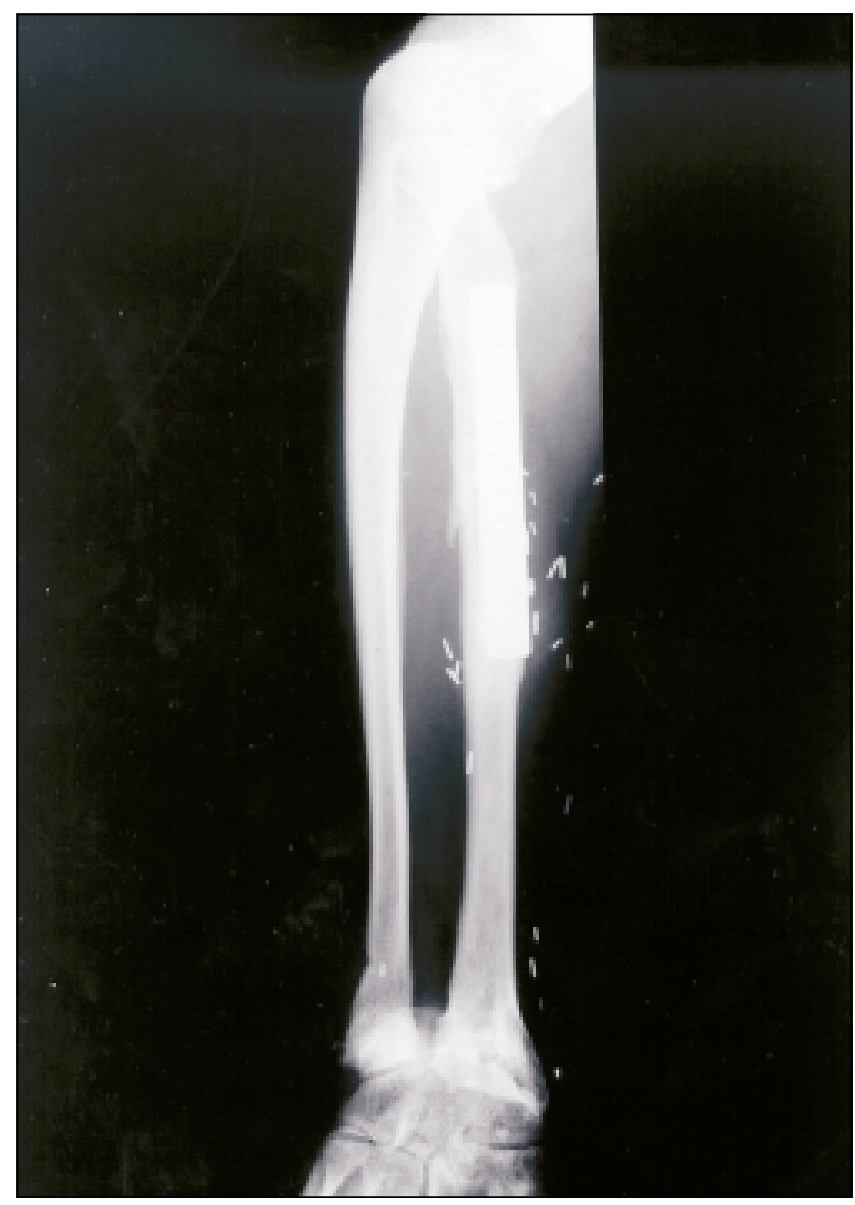

Figure 11) Case 2: X-ray performed 16 years postoperatively showing fibular transplant in place

The physis has a limited ability to withstand ischemia. Normal growth can be expected from a physis subject to under $3 \mathrm{~h}$ of warm ischemia, while greater than $7 \mathrm{~h}$ of warm ischemia severely lessens the physeal growth potential (21). Thus, the choice of single versus double pedicle anastomosis is influenced by the ischemic time.

In case 1, a double pedicle anastomosis was completed in less than $7 \mathrm{~h}$ with no vascular compromise of the epiphysis. Only the peroneal blood supply was used in case 2 . This patient was near skeletal maturity, and decreased growth due to metaphyseal supply alone is unlikely.

Endocrine environment: Although endocrine agents are known to affect growing bone, no studies have directly examined their effect on the growth potential of epiphyseal transplants. Thyroxine, growth hormone, testosterone and estrogen all play a role in normal bone growth and development (25). Further work may reveal optimal conditions that would enhance bone growth.

Innervation: Abnormal limb innervation can cause growth disturbance and joint degeneration secondary to decreased muscle tone and trauma associated with an insensate joint (27). Attachment of muscles to the transferred bone at the host 
site promotes normal growth and may improve position sense. In case 2, pronator and supinator muscles were sutured to the fibular transplant. The patient showed growth and even hypertrophy of the bone, and was capable of pronation and supination. Nettelblad et al (10) suggested that the problem of joint degeneration due to denervation of the epiphyseal transplant could be averted with adequate protection of the reconstructed limb early in recovery. Both of our patients received protective casts and, although the second patient developed hypertrophy and volar subluxation, neither had ongoing degeneration consistent with a charcot joint.

Recipient site factors: Differences in the outcome of limb reconstruction for tumour, trauma or congenital anomaly have not been reported. Children with tumours frequently have undergone extensive chemotherapy or radiation treatment; those with trauma may have tenuous blood supply and innervation, and increased risk of infection, and those with congenital anomalies may have diffuse underlying bone or cartilage abnormalities. Investigating the role of these complicating factors is necessary for accurate prediction of graft result. Each of our patients had bone tumours and completed a course of chemotherapy before surgery. The second patient also underwent chemotherapy postoperatively. While radiation is known to damage physes and inhibit growth, the effects of chemotherapy are less defined. Small growth impairments have been described with some chemotherapeutics (28).

Donor site factors: Donor site considerations include complications of tissue removal and the effects of tissue loss as well as the properties of the transferred tissue. Experimental models do not describe instability, weakness, decreased range of motion or nerve injuries at the donor sites. No donor site problems were reported by our patients. Bone transferred using the microvascular technique maintains the same growth rate, growth potential and closure of epiphyses as it would at the donor site (2). The fibula grows an average of $0.64 \mathrm{~cm} /$ year. The distal epiphysis ossifies near two years of age and closes at about 14 years of age. The proximal epiphysis ossifies near four years of age and closes at about 16 years of age. The proximal epiphysis contributes approximately $60 \%$ of the longitudinal growth of the fibula (29).

Mechanical stressors: Stress on bones is the result of weight bearing and tension at muscle insertions. Changing the compression, tension and shear forces experienced by physes results in a change in growth properties and remodelling of the bone $(2,9,10,12,17,25)$. The Heuter-Volkmann law of cartilage growth suggests that an increase in tension or compression within a physiological range stimulates growth (25). Stresses that exceed these physiological limits may stop growth. The physiological limits on stress have not been described for the fibula. The change in stress as a result of transplantation may, therefore, be stimulatory or abortive. Ideally, bones should be transplanted to areas of similar stress profile. The development of different physeal models may make this possible.

\section{Clinical experience}

Before the advent of microvascular surgery, epiphyseal plate transfer had limited clinical application. Nonvascularized grafts had been used with limited success with small epiphyses, such as phalanges, and with patients under 18 months of age (30). These grafts survived the period of ischemia by tissue fluid diffusion. Initial clinical work using vascularized epiphyseal grafts employed small physes of the hands and feet, but subsequent case reports have shown successful transfer of the larger physis of the fibula. Vascularized grafting has allowed transfer of larger donor physes, thereby increasing flexibility in limb reconstruction.

Some of the earliest reported clinical work was carried out in 1984 by O'Brien et al (1), who transferred vascularized metatarsophalangeal (MTP) and proximal interphalangeal (PIP) joints of the toes to the MTP and PIP of the hands of four children who had experienced trauma. Their long term results (six to eight years) showed painless functional and stable joints. Better growth and range of motion resulted from the MTP to metacarpalphalangeal transfers than with the toe to finger PIP transfers (31).

In 1988, Pho et al (2) described two cases in which the proximal fibula, based on the peroneal artery, was transferred to the distal radius and one case where the proximal fibula was transferred to the upper humerus. In all three cases, open epiphyses were maintained, but less than normal growth was observed. Complications at the recipient site included fragmentation of the transferred epiphysis, reoperation for ulnar deviation and resorption of the proximal graft.

In 1986, Tsai et al (29) published eight cases of transplantation of the fibular epiphysis for the reconstruction of upper limb defects. In seven cases, a single branch of the anterior or posterior tibial artery was used, and, in one case the LIG artery and the peroneal artery were anastamosed. Of the first seven cases, three suffered early closure of the epiphyses and the growth rates ranged from 0 to $0.4 \mathrm{~cm} /$ year. In the other case, a complete blood supply was provided to the physis and the growth rate was $1.2 \mathrm{~cm} /$ year. In 1988, Taylor et al (5) described two cases of proximal fibular epiphysis transplanted to the forearm and proximal tibia based on the anterior tibial artery alone. In both cases, the fibula showed growth of $1 \mathrm{~cm} /$ year. The fibula transplanted to the proximal tibia hypertrophied and contributed to leg stability. Following the work of Taylor et al, Sawaizumi et al (6) successfully transplanted a fibular epiphysis based on the anterior tibial artery for the correction of a radial club hand, and Concannon et al (7) used a proximal fibular graft based on the peroneal artery to compensate for a valgus foot deformity. Both groups reported near normal growth and normal ambulation, although recurrence of valgus deformity was noted after five years of follow-up.

These case reports highlight the relationship between adequate vascular supply to the epiphysis and the amount of bone growth obtained. Malalignment and joint deterioration are commonly reported problems in vascularized epiphyseal plate transplantation. Malalignment is usually a varus or valgus deformity that occurs when the fibula is transplanted to a 
joint in which two bones are required for joint support, such as the radius and ulna at the wrist, and the tibia and fibula at the ankle. Growth discrepancies and unbalanced forces are likely causative. Joint incongruity creates foci of increased stress when the proximal fibula is transplanted to an articular surface such as the wrist or the ankle mortise. This abnormal distribution of forces at the joint, perhaps in combination with decreased joint sensation, causes joint sclerosis and subsequent deterioration. Decancellation for reshaping while maintaining the integrity of the articular surface, periosteum and physis is a possible solution - this was attempted in case 1. Asymmetric tibial growth contributed to joint destruction making joint congruity at the new lateral malleolus difficult to evaluate.

In case 1, the peroneal artery, in combination with the LIG artery, should have maintained epiphyses capable of moderate to normal growth. The fibular epiphysis continued to grow; however, malalignment was a significant problem, making growth measurements for the fibular transplant impossible. The patient required a corrective osteotomy for a valgus deformity. Ironically, in this case the valgus deformity was the result of premature epiphyseal closure at the tibial epiphysis and not the vascularized transplant. Decancellation of the fibular transplant was performed in this patient, and her long-term outcome shows a well-preserved joint space with no joint deterioration. In case 2, muscular rebalancing was performed and epiphyseal growth was sufficient for wrist stability in flexion and extension with no significant radial deviation. The second patient suffered a volar subluxation of the wrist caused by ulnar carpal ligament deficiency. This resulted in a decreased range of motion, but no evidence of progressive joint deterioration.

\section{SUMMARY}

The current indications for vascularized epiphyseal transplantation include tumour, congenital abnormality or trauma resulting in significant or complete loss of a long bone or digits in a growing patient. The majority of clinical experience to date is with the vascularized transplantation of fibular, MTP joint and PIP joint epiphyses. Vascularized epiphyseal grafts have the advantages of improved wound healing and rapid bone union compared with nonvascularized grafts. The epiphyseal grafts also offer growth potential that would not exist with a nonepiphyseal transplant. Vascularized epiphyseal transplantation is a very flexible technique with many potential applications. This flexibility has been demonstrated by Shenaq and Dinh (32), who described the use of an iliac osteocutaneous vascularized epiphyseal transplant for the reconstruction of a heel.

In fibular transplantation where the fibular head is included and the blood supply to the epiphysis is maintained, our preferred technique is the use of the anterior tibial vessels. This method has been clearly shown to maintain the vascularity of the growth plate, involves larger vessels and requires only one set of vascular repairs. The formation of a solid union allowed our patients to maintain stable and functional limbs. Both patients demonstrated near normal growth of the transplanted fibula. Major complications with these grafts are malalignment and joint destruction. The first patient required reoperation for valgus deformity, and the second patient had decreased range of wrist motion. Although excess growth of the graft may contribute to joint malalignment, normal bone outgrows the stationary graft in nonepiphyseal grafts. Decancellation of bone may help to overcome problems with joint degeneration. Muscular rebalancing may help promote normal bone growth, provide adequate range of motion and improve position sense in the limb. In the two cases presented, these important concepts in vascular epiphyseal transplantation are illustrated.

\section{REFERENCES}

1. O'Brien BM, Gould JS, Morrison WA, Russell RC, MacLeod AM, Pribaz JJ. Free vascularized small joint transfer to the hand. J Hand Surg [Am] 1984;9:634-41.

2. Pho RWH, Patterson MH, Kour AK, Kumar VP. Free vascularized epiphyseal transplantation in upper extremity reconstruction. J Hand Surg [Br] 1988;13:440-7.

3. Singer DI, O'Brien BM, Angel MF, Gumley GJ. Digital distraction lengthening followed by free vascularized epiphyseal joint transfer. J Hand Surg [Am] 1989;14:508-12.

4. Kleinert HE. Bone and osteocutaneous microvascular free flaps. J Hand Surg [Am] 1983;8:735-7.

5. Taylor GI, Wilson KR, Rees MD, Corlett RJ, Cole WG. The anterior tibial vessels and their role in epiphyseal and diaphyseal transfer of the fibula: experimental study and clinical applications. Br J Plast Surg 1988;41:451-69.

6. Sawaizumi M, Maruyama Y, Okajima K, Motegi M. Free vascularised epiphyseal transfer designed on the reverse anterior tibial artery. Br J Plast Surg 1991;44:57-9.

7. Concannon MJ, Croll GH, Boschert MT, Gaines RW, Puckett CL. Free fibular transfer in a growing individual (long-term results). Microsurgery 1993;14:624-7.

8. Donski PK, O’Brien BM. Free microvascular epiphyseal transplantation: an experimental study in dogs. Br J Plast Surg 1980;33:169-78.

9. Teot L, Bosse JP, Gilbert A, Tremblay GR. Pedicle graft epiphysis transplantation. Clin Orthop 1983;180:206-18.

10. Nettelblad H, Randolph MA, Weiland AJ. Heterotopic microvascular growth plate transplantation of the proximal fibula: an experimental canine model. Plast Reconstr Surg 1986;77:814-20.

11. Donski PK, Carwell GR, Sharzer LA. Growth in revascularized bone grafts in young puppies. Plast Reconstr Surg 1979;64:239-43.

12. Bowen CVA, Crosby NL, Wilkinson AA, Cassidy JD, Johnson GHF. A study of the effects of loading on microsurgical free growth plate transfers. Orthop Trans 1987;11:414.

13. Brown K, Marie P, Lyszakowski T, Daniel R, Cruess R. Epiphysial growth after free fibular transfer with and without microvascular anastamosis. J Bone Joint Surg [Br] 1983;65:493-501.

14. Tomita Y, Tsai T, Steyers C, Ogden L, Jupiter JB, Kutz JE. The role of the epiphyseal and metaphyseal circulation on the longitudinal growth in the dog: an experimental study. J Hand Surg [Am] 1986;11:375-82.

15. Bowen CVA, Ethridge CP, O’Brien BM, Frykman GK, Gumley GJ. Experimental microvascular growth plate transfers. Part 1 Investigation of vascularity. J Bone Joint Surg [Br] 1988;70:305-10.

16. Bowen CVA, O’Brien BM, Gumley GJ. Experimental microvascular growth plate transfers: Part 2 - Investigation of feasibility. J Bone Joint Surg [Br] 1988;70:311-4.

17. Brown KLB, Kornacki JB, Welter JF, Poole AR, Cruess RL. The effects of weightbearing on the growth of heterotopically transplanted free vascularized epiphyseal grafts in dogs. Orthop Trans 1986;10:241-2.

18. Zaleske DJ, Ehrlich MG, Piliero C, May JW Jr, Mankin HJ. 
Growth-plate behaviour in whole joint replantation in the rabbit. J Bone Joint Surg 1982;64:249-57.

19. Nolan LM, Bowen CVA, Boyer MI. Skeletal fixation in the rabbit knee transplantation model. Microsurgery 1992;13:291-2.

20. Stevens D, Bowen CVA. Heterotopic microvascular epiphyseal plate transplantation: a new model using the rabbit metatarsal. Microsurgery 1995;16:488-92.

21. Stark RH, Matloub HS, Sanger JR, Cohen EB, Lynch K. Warm ischemic damage to epiphyseal growth plate: a rabbit model. J Hand Surg [Am] 1987;12:54-61.

22. Zalske DJ, Floyd WE 3rd, Hallet J, et al. Epiphyseal replacement using developing tissue donors in a murine model: a combined histologic and radiographic study. J Orthop Res 1988;6:155-65.

23. Saravese JJ 3rd, Brinken BW, Zalske DJ. Epiphyseal replacement in a murine model. J Pediatr Orthop 1995;15:682-90.

24. Gutlan SM, Emiroglou M, Cenetoglou IS, Yormuk E. Effects of free perichondrial graft replacement of epiphyseal cartilage on bone growth. Scand J Plast Reconstr Surg Hand Surg 1993;27:1-8.
25. Ogden JA, Urist MR. Fundamental and Clinical Bone Physiology. New York: JB Lippincott, 1980:163.

26. Bowen CVA, Singer S. Bernard O'Brien: the microsurgical transfer of immature bone. Microsurgery 1994;15:733-7.

27. Ring PA. The Influence of the nervous system upon the growth of bones. J Bone Joint Surg [Br] 1961;43:121-40.

28. Goldwein JW. Influence of radiation on growth in pediatric patients. Clin Plast Surg 1993:20:455-64.

29. Tsai T, Ludwig L, Tonkin M. Vascularized fibular epiphyseal transfer: a clinical study. Clin Orthop 1986;210:228-34.

30. Goldberg NH, Watson HK. Composite toe (phalanx and epiphysis) transfers in the reconstruction of the aphalangic hand. J Hand Surg 1982;7:454-9.

31. Singer DI, O'Brien BM, McLeod AM, Morrison WA, Angel MF. Long-term follow-up of free vascularized joint transfers to the hand in children. J Hand Surg [Am] 1988;13:776-83.

32. Shenaq SM, Dinh TA. Heel reconstruction with an iliac osteocutaneous free flap in a child. Microsurgery 1989;10:93-8. 